Check for updates

Cite this: RSC Adv., 2017, 7, 30109

\title{
Amino acid-modified graphene oxide magnetic nanocomposite for the magnetic separation of proteins $\uparrow$
}

\begin{abstract}
Min Yan, (D) Qionglin Liang, * Wei Wan, Qiang Han, Siyuan Tan and Mingyu Ding*
A novel amino acid-modified graphene oxide magnetic nanocomposite was successfully synthesized for the magnetic separation of proteins. The extraction capacity was influenced by several parameters including the type of amino acid, the solution $\mathrm{pH}$ value, the addition of electrolyte, the extraction time and the protein concentration. The nanocomposite showed excellent extraction capacity for bovine hemoglobin ( $868.3 \mathrm{mg} \mathrm{g}^{-1}$ ). By adsorbing bovine hemoglobin, bovine serum albumin, ovalbumin and lysozyme, the nanocomposite had a better performance than magnetic graphene oxide in the extraction of bovine hemoglobin and lysozyme, owing to the intensive electrostatic interaction. The proposed nanocomposite could be easily recycled and reused more than three times. Moreover, the proposed method was successfully applied to selectively extract bovine hemoglobin in acid protein mixtures and real samples.
\end{abstract}

Received 6th May 2017

Accepted 30th May 2017

DOI: $10.1039 / \mathrm{c} 7 \mathrm{ra05114j}$

rsc.li/rsc-advances

cost technique that requires no cumbersome operation and offers high extraction efficiency, and is widely used in sample pretreatment procedures. ${ }^{11-13}$

Graphene (G) is a novel carbon-based material with twodimensional properties. ${ }^{14}$ It has attracted a great amount of research interest because of its physical and chemical properties such as extraordinary electrical conductivity, and excellent thermal and mechanical qualities. ${ }^{15-18}$ In addition, graphene has been widely used in sample pretreatment owing to its large specific surface area, good dispersibility and hydrophobicity. ${ }^{19,20}$ Graphene oxide (GO), the oxidation product of graphene, is considered to be an ideal adsorbent material in analytical chemistry. ${ }^{21}$ On one hand, GO still maintains the basic framework of graphene, which means it has a huge surface area. On the other hand, there are many oxygenated groups on the surface of GO, such as epoxy, hydroxyl and carboxyl, making GO more hydrophilic. ${ }^{22}$ Furthermore, the functional groups can form hydrogen bonding and electrostatic interactions with adsorbates, and can tune the adsorption properties of specific adsorbates via functional modification..$^{23}$ Therefore, GO has potential for sample pretreatment. However, it is difficult to separate GO from aqueous solution, which limits its direct use in sample pretreatment. To overcome this drawback, graphene hybrid materials have become the research focus. Magnetic GO possesses high adsorption capacity and can be easily separated by an external magnetic field, which indicates good potential in magnetic separation applications. ${ }^{24}$ Recently, magnetic GO has been applied as the sorbent for organic compounds ${ }^{25}$ heavy metal ions ${ }^{26}$ phosphopeptides ${ }^{27}$ and proteins. ${ }^{28}$ Moreover, Ding et al. modified the functional guanidinium ionic liquids on GO to synthesize a magnetic 
composite material, which improved the extraction capacity of proteins. ${ }^{29}$ Modification of the oxygenated groups on GO seems to be a good approach to enhance the extraction efficiency of proteins.

Amino acids, the basic building units of protein, exhibit good biocompatibility. ${ }^{30}$ In addition, they possess functional groups such as amino, carboxyl, phenyl and sulfhydryl groups which can form hydrogen bonding, electrostatic and $\pi-\pi$ interactions with proteins. Modification of the amino acids on GO can improve the biocompatibility and adsorbability of the adsorbents. However, modification of amino acids on GO as the absorbent for proteins has rarely been reported.

In this paper, amino acid-modified graphene oxide magnetic nanocomposite (AMGO@ $\mathrm{Fe}_{3} \mathrm{O}_{4}$ ) was synthesized for the magnetic separation of proteins. We have chosen four kinds of amino acid with different functional groups to modify the surface of GO. Bovine hemoglobin $(\mathrm{BHb})$ was selected as the representative protein to explore the adsorption capacity. After adsorption, the concentration of protein in the supernatant was measured by a UV-vis spectrophotometer. The parameters influencing extraction efficiency, including $\mathrm{pH}$ value, addition of electrolyte, extraction time and protein concentration, were optimized in detail. AMGO@ $\mathrm{Fe}_{3} \mathrm{O}_{4}$ has also been used to explore extraction selectivity, and the results indicated that it could selectively extract $\mathrm{BHb}$ in an acidic protein mixture and in real samples.

\section{Materials and methods}

\subsection{Materials}

Expanded graphite powder (100 mesh) was supplied by the Xinghe Graphite Co., Ltd (Qingdao, China). Amino acids were obtained from Beijing Chemical Reagent Co. (Beijing, China). 1Ethyl-3-(3-dimethylaminopropyl)carbodiimide hydrochloride (EDC) was purchased from J\&K Chemical Technology Co., Ltd (Beijing, China). Ferric chloride and ferrous chloride were bought from Xilong Chemical Co., Ltd (Guangdong, China). Ammonia solution (25\%) was acquired from Beijing Chemical Works (Beijing, China). Proteins including bovine hemoglobin (BHb), bovine serum albumin (BSA) and lysozyme (Lyz) were obtained from Beijing Keao Biological Pharmaceutical Co., Ltd (Beijing, China). Ovalbumin (OVA) was from Beijing Century Hualin Biotechnology Co., Ltd (Beijing, China). Bovine plasma was purchased from Beijing Keao Biological Pharmaceutical Co., Ltd (Beijing, China). All other reagents used in this study were analytical grade, and deionized water was used throughout the work.

\subsection{Preparation of GO}

GO was synthesized from expanded graphite powder following a modified Hummers' method..$^{31}$ About $18 \mathrm{~g}$ of potassium permanganate was added into a mixture of frozen concentrated $\mathrm{H}_{2} \mathrm{SO}_{4}(360 \mathrm{~mL})$ and $\mathrm{H}_{3} \mathrm{PO}_{4}(40 \mathrm{~mL})$, then $3 \mathrm{~g}$ of expanded graphite powder was slowly added with vigorous agitation to avoid a sudden increase in temperature. The reaction was maintained at $50{ }^{\circ} \mathrm{C}$ for $12 \mathrm{~h}$. After this, the mixture was transferred into an ice-water mixture with the same volume, and $30 \% \mathrm{H}_{2} \mathrm{O}_{2}$ was added dropwise until the color of the slurry turned to golden yellow. The slurry was washed with $10 \% \mathrm{HCl}$ and deionized water and centrifuged to remove the supernatant. Then the product was purified by dialysis for 1 week to remove the remaining metal species. After the dialysis, the GO was ultrasonicated for $2 \mathrm{~h}$ to obtain an aqueous dispersion $\left(10 \mathrm{mg} \mathrm{mL}^{-1}\right)$.

\subsection{Preparation of AMGO}

EDC (0.25 g) was added into $10 \mathrm{~mL}$ GO aqueous dispersion (10 $\mathrm{mg} \mathrm{mL} \mathrm{mL}^{-1}$ ) under agitation. After stirring for $30 \mathrm{~min}$, different amino acids (0.3 g each) including L-arginine (Arg), glutamic acid (Glu), phenylalanine (Phe) and cysteine (Cys) were added to separate GO/EDC solutions. The mixtures were stirred for $24 \mathrm{~h}$ at room temperature. Then the amino acid-modified GO materials (AMGO) were washed with deionized water and centrifuged 5 times to remove the unreacted amino acids. Finally, the materials were dried in oven at $60{ }^{\circ} \mathrm{C}$ for $12 \mathrm{~h}$.

\subsection{Preparation of AMGO@ $\mathrm{Fe}_{3} \mathrm{O}_{4}$}

AMGO@Fe $\mathrm{F}_{3} \mathrm{O}_{4}$ was synthesized by the chemical coprecipitation method. ${ }^{26}$ The synthesized AMGO was dispersed in deionized water and ultrasonicated for $6 \mathrm{~h}$ to obtain an aqueous dispersion of AMGO $\left(1 \mathrm{mg} \mathrm{mL}{ }^{-1}\right)$. Then, $250 \mathrm{mg}$ of ferric chloride and $500 \mathrm{mg}$ of ferrous chloride were added slowly to $50 \mathrm{~mL}$ of the AMGO dispersion at $50{ }^{\circ} \mathrm{C}$ under $\mathrm{N}_{2}$. Afterwards, $2 \mathrm{~mL}$ of ammonia solution was added slowly for synthesis of magnetite particles, and the reaction was maintained under vigorous stirring for $30 \mathrm{~min}$. Then the mixture was subjected to an external magnetic field to separate the AMGO@ $\mathrm{Fe}_{3} \mathrm{O}_{4}$. Finally, the AMGO@ $\mathrm{Fe}_{3} \mathrm{O}_{4}$ was washed with deionized water 5 times and dispersed in deionized water $\left(2 \mathrm{mg} \mathrm{mL}^{-1}\right)$.

\subsection{Magnetic separation procedures}

Magnetic separation experiments were performed using the AMGO@Fe ${ }_{3} \mathrm{O}_{4}$ as the adsorbent and $\mathrm{BHb}$ as the target protein to examine the extraction capacity. A $1 \mathrm{~mL}$ portion of the homogenized adsorbent solution $\left(2 \mathrm{mg} \mathrm{mL}^{-1}\right)$ was placed in a centrifuge tube. The adsorbent was isolated using an external magnetic field to remove the supernatant. Then $2 \mathrm{~mL}$ of aqueous protein solution was transferred into the centrifuge tube and the mixture was shaken at room temperature for $1 \mathrm{~h}$. Afterwards, AMGO@ $\mathrm{Fe}_{3} \mathrm{O}_{4}$ was magnetically separated by an external magnetic field. The concentration of protein in the supernatant was measured by a UV-vis spectrophotometer at the maximum absorption wavelength.

\subsection{Characterization of graphene nanocomposites}

Fourier transform infrared spectra were recorded in the range 4000-500 $\mathrm{cm}^{-1}$ on a Bruker Fourier Transform Infrared Spectrometer (Horiba, Germany). The magnetic properties were measured with a 7307 Vibrating Sample Magnetometer (LakeShore, USA). X-ray photoelectron spectroscopy data were evaluated using a PHI-5300 ESCA X-ray photoelectron spectrometer 
(PHI, USA). Transmission electron microscopy images were taken with an H-7650B transmission electron microscope (Hitachi, Japan). Ultraviolet visible detection was carried out on a U-3010 UV-vis spectrophotometer (Hitachi, Japan). Zeta potential data were measured using a SZ-100 Nanoparticle Analyzer (Horiba, Japan).

\section{Results and discussion}

\subsection{Characterization of AMGO@ $\mathrm{Fe}_{3} \mathrm{O}_{4}$}

The AMGO@ $\mathrm{Fe}_{3} \mathrm{O}_{4}$ synthesis procedure is illustrated schematically in Fig. 1. First, GO was prepared by the modified Hummers' method, and then the oxygenated groups including epoxy, hydroxyl and carboxyl were introduced to the surface of graphene. Second, the amide reaction occurred between the amine groups of amino acids and the carboxyl groups of GO, introducing amino acids to the surface of GO. Elemental analysis results showed that the content of nitrogen increased from $0.58 \%$ to $8.21 \%$, and the content of carbon decreased from $44.25 \%$ to $38.91 \%$ after modification. Third, the AMGO@ $\mathrm{Fe}_{3} \mathrm{O}_{4}$ was synthesized by the chemical coprecipitation method. The iron ions $\left(\mathrm{Fe}^{2+}\right.$ and $\left.\mathrm{Fe}^{3+}\right)$ were seized on the surface of the AMGO sheets and then the $\mathrm{Fe}_{3} \mathrm{O}_{4}$ precipitate formed in the presence of ammonia solution. Finally, the nanocomposites we required were obtained.

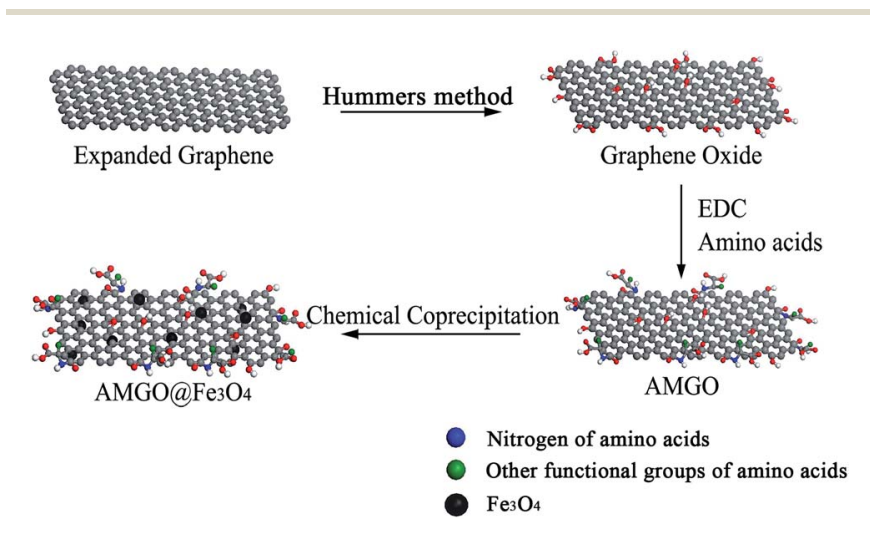

Fig. 1 Schematic illustration of the synthesis of $\mathrm{AMGO}_{\mathrm{aFe}} \mathrm{O}_{4}$ AMGO, amino acid-modified graphene oxide; EDC, 1-ethyl-3-(3dimethylaminopropyl)carbodiimide hydrochloride.
We chose the glutamic acid modified magnetic composite AMGO-Glu@ $\mathrm{Fe}_{3} \mathrm{O}_{4}$ as the model to study the physical and chemical properties.

3.1.1 Fourier transform infrared spectrometry. FTIR was carried out to identify the successful modification of amino acids and magnetic particles and the results are shown in Fig. S1. $\dagger$ For the FTIR spectrum of GO, the peaks at $1719.5 \mathrm{~cm}^{-1}$ and $1618.2 \mathrm{~cm}^{-1}$ were attributed to $\mathrm{C}=\mathrm{O}$ and $\mathrm{C}=\mathrm{C}$ stretching vibrations, respectively, indicating the successful oxidation process. $^{30}$ For the FTIR spectra of AMGO-Glu and AMGOGlu@Fe $\mathrm{O}_{4}$, the peaks at $1617.3 \mathrm{~cm}^{-1}$ and $1380.9 \mathrm{~cm}^{-1}$ were assigned to the $\mathrm{C}=\mathrm{O}$ stretching vibration and $\mathrm{C}-\mathrm{N}$ bending vibration of -NHCO-, respectively. ${ }^{29}$ The peak at $1576.8 \mathrm{~cm}^{-1}$ corresponded to the $\mathrm{N}-\mathrm{H}$ bending vibration. The results indicated that the amino acids had been covalently grafted to the surface of GO. In addition, both the $\mathrm{GO} @ \mathrm{Fe}_{3} \mathrm{O}_{4}$ and AMGOGlu@Fe ${ }_{3} \mathrm{O}_{4}$ presented a sharp peak at $578.6 \mathrm{~cm}^{-1}$ attributed to the $\mathrm{Fe}-\mathrm{O}$ stretching vibration. This proved the existence of $\mathrm{Fe}_{3} \mathrm{O}_{4}$.

3.1.2 Vibrating sample magnetometer (VSM). A VSM was used to study the magnetic properties of the synthesized materials at room temperature. The magnetization curves of GO@ $\mathrm{Fe}_{3} \mathrm{O}_{4}$ and AMGO-Glu@ $\mathrm{Fe}_{3} \mathrm{O}_{4}$ are shown in Fig. 2A. The saturation magnetization values of $\mathrm{GO} @ \mathrm{Fe}_{3} \mathrm{O}_{4}$ and AMGOGlu@Fe $\mathrm{O}_{4}$ were $45.77 \mathrm{emu} \mathrm{g}^{-1}$ and $60.56 \mathrm{emu} \mathrm{g}^{-1}$, respectively. This may be because the negative charge of AMGO-Glu increased after modification, and more iron ions were seized on the surface of the AMGO-Glu sheets, which increased the load amount of $\mathrm{Fe}_{3} \mathrm{O}_{4}$. Both $\mathrm{GO} @ \mathrm{Fe}_{3} \mathrm{O}_{4}$ and AMGO-Glu@ $\mathrm{Fe}_{3} \mathrm{O}_{4}$ exhibited superparamagnetic properties according to the S-like magnetic hysteresis loops. Fig. 2B illustrates that AMGOGlu@Fe $\mathrm{O}_{4}$ could be quickly separated from the dispersion when an external magnetic field was applied, which is important for further research.

3.1.3 X-ray photoelectron spectroscopy. XPS spectra were used to further investigate the presence of functional groups on AMGO@Fe $\mathrm{O}_{4}$. As shown in Fig. 3A, all of the materials showed the same peaks at approximately 285 and $530 \mathrm{eV}$, which were attributed to $\mathrm{C} 1 \mathrm{~s}$ and $\mathrm{O} 1 \mathrm{~s}$, respectively. ${ }^{5}$ The peaks at about $710 \mathrm{eV}$ for $\mathrm{GO} @ \mathrm{Fe}_{3} \mathrm{O}_{4}$ and AMGO-Glu@ $\mathrm{Fe}_{3} \mathrm{O}_{4}$ were consistent with the characteristic peaks of Fe 2p. In Fig. 3D, the peaks at $711.3 \mathrm{eV}$ and $724.8 \mathrm{eV}$, which corresponded to $\mathrm{Fe} 2 \mathrm{p}_{2 / 3}$ and $\mathrm{Fe}$
(A)

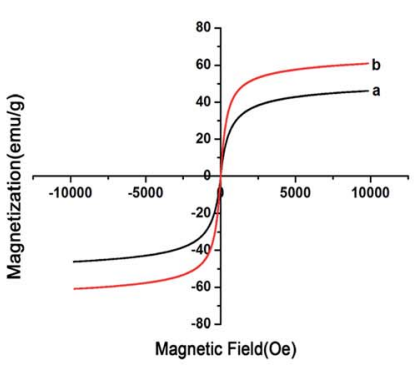

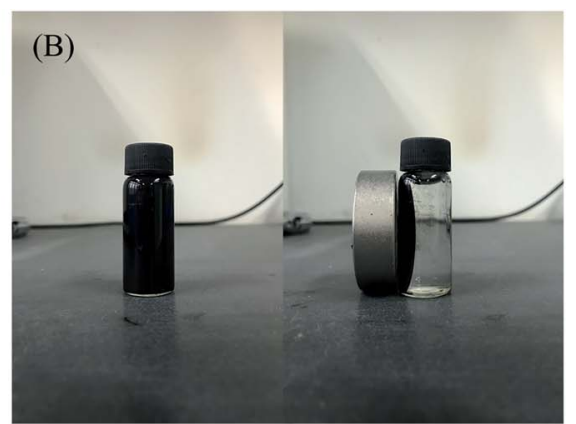

Fig. 2 (A) Magnetic hysteresis loops of $\mathrm{GO} \mathrm{AFe}_{3} \mathrm{O}_{4}$ (a) and $\mathrm{AMGO}-\mathrm{GluaFe} \mathrm{O}_{4}$ (b), and (B) response of $\mathrm{AMGO}-\mathrm{GluaFe}_{3} \mathrm{O}_{4}$ to an external magnetic field. 
(A)

$2 \mathrm{p}_{1 / 2}$, indicated the formation of the $\mathrm{Fe}_{3} \mathrm{O}_{4}$ phase in the composites. $^{26}$ The peak at about $400 \mathrm{eV}$ for AMGO-Glu@ $@ \mathrm{Fe}_{3} \mathrm{O}_{4}$ (Fig. 3A and C) was attributed to $\mathrm{N} 1 \mathrm{~s}$, illustrating the existence of nitrogen from amino acids. The $\mathrm{C} 1 \mathrm{~s}$ spectra of AMGOGlu@ $\mathrm{Fe}_{3} \mathrm{O}_{4}$ (Fig. 3B) could be deconvoluted into four fitting curves with peaks located at about 284.8, 285.6, 286.6, and $288.8 \mathrm{eV}$, assigned to $\mathrm{C}-\mathrm{C}, \mathrm{C}-\mathrm{N}, \mathrm{C}-\mathrm{O}$, and $\mathrm{C}=\mathrm{O}$, respectively. ${ }^{5}$ The appearance of $\mathrm{C}-\mathrm{N}$ confirmed the successful modification of GO with amino acids.

3.1.4 Transmission electron microscopy. The morphologies of GO, AMGO and AMGO@ $\mathrm{Fe}_{3} \mathrm{O}_{4}$ were characterized by transmission electron microscopy. From Fig. 4A, it can be seen that GO had a flake-like shape with some corrugations. After modification of amino acids, the morphology of AMGO-Glu was still a folded and wrinkled sheet (Fig. 4B), which meant that AMGO-Glu retained the characteristic of a large surface area. Fig. 4C and $\mathrm{D}$ show that the $\mathrm{Fe}_{3} \mathrm{O}_{4}$ nanoparticles were distributed on the surface of AMGO-Glu, which indicated the successful synthesis of $\mathrm{Fe}_{3} \mathrm{O}_{4} \cdot{ }^{25}$

\subsection{Optimization of the magnetic separation conditions}

Bovine hemoglobin $(\mathrm{BHb})$ was chosen as the representative protein to study the extraction capacity of the prepared Glua $\mathrm{Fe}_{3} \mathrm{O}_{4}$
(B)

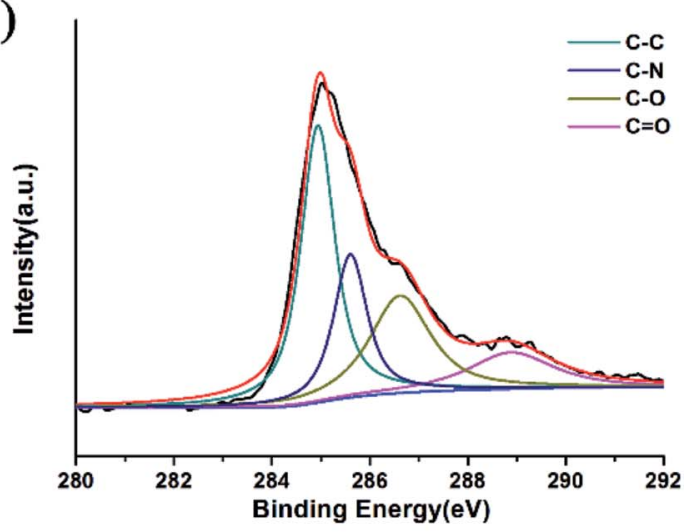

(D)

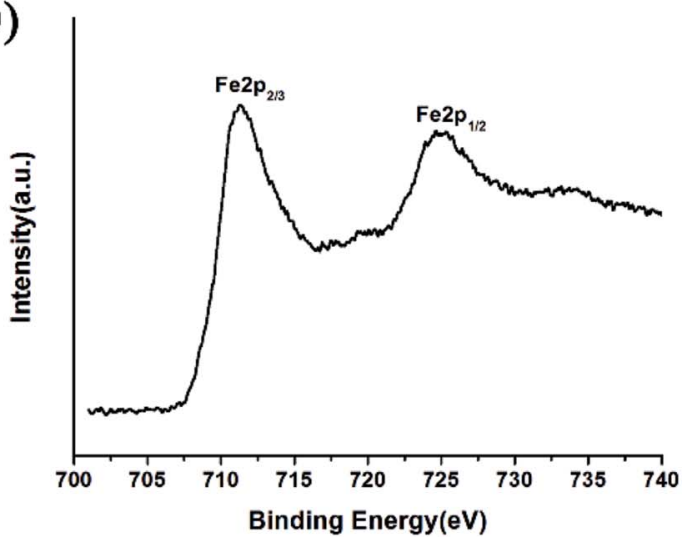

Fig. 3 XPS spectra of (A) wide scan of $\mathrm{GO}$ (a), GOQFe $\mathrm{O}_{4}$ (b) and $\mathrm{AMGO}-\mathrm{GluaFe} \mathrm{O}_{4}$ (c), (B) C 1s, (C) N 1s, and (D) Fe 2p spectra of AMGO-

AMGO@Fe $\mathrm{O}_{4}$. The extraction amount was calculated according to the following formula: ${ }^{26}$

$$
Q_{\mathrm{e}}=\frac{\left(C_{\mathrm{i}}-C_{\mathrm{e}}\right) V}{m}
$$

where $Q_{\mathrm{e}}\left(\mathrm{mg} \mathrm{g}^{-1}\right)$ is the mass of protein extracted by unit mass of AMGO@ $\mathrm{Fe}_{3} \mathrm{O}_{4}, C_{\mathrm{i}}\left(\mathrm{mg} \mathrm{mL}^{-1}\right)$ and $C_{\mathrm{e}}\left(\mathrm{mg} \mathrm{mL} \mathrm{mL}^{-1}\right)$ are the initial and equilibrium protein concentrations, $V(\mathrm{~mL})$ is the volume of the initial solution and $m(\mathrm{~g})$ is the weight of the adsorbent based on the dry weight of AMGO@ $\mathrm{Fe}_{3} \mathrm{O}_{4}$.

Several factors including the type of amino acid, $\mathrm{pH}$ value, addition of electrolyte, extraction time, and protein concentration were optimized to attain the best adsorption efficiency.

3.2.1 Effect of the type of amino acid. As shown in Table $\mathrm{S} 1, \uparrow$ four kinds of amino acid have been selected to modify the surface of GO in this experiment. All of the extraction experiments were carried out at room temperature. The extraction capacities of the four kinds of AMGO@ $\mathrm{Fe}_{3} \mathrm{O}_{4}$ are shown in Fig. 5. The results indicated that the extraction amounts of the adsorbents were different (AMGO-Glu@ $\mathrm{Fe}_{3} \mathrm{O}_{4}: 868.3 \mathrm{mg} \mathrm{g}^{-1}$, AMGO-Arg@Fe $\mathrm{O}_{4}: 647.5 \mathrm{mg} \mathrm{g}^{-1}$, AMGO-Cys@ $\mathrm{Fe}_{3} \mathrm{O}_{4}: 769.9 \mathrm{mg}$ $\mathrm{g}^{-1}$, AMGO-Phe@ $\mathrm{Fe}_{3} \mathrm{O}_{4}: 600.6 \mathrm{mg} \mathrm{g}^{-1}$ ) for the same protein $\mathrm{BHb}$. This phenomenon might be explained by the multiple interactions between protein and adsorbent including electrostatic, hydrogen bonding and $\pi-\pi$ interactions. When the four 


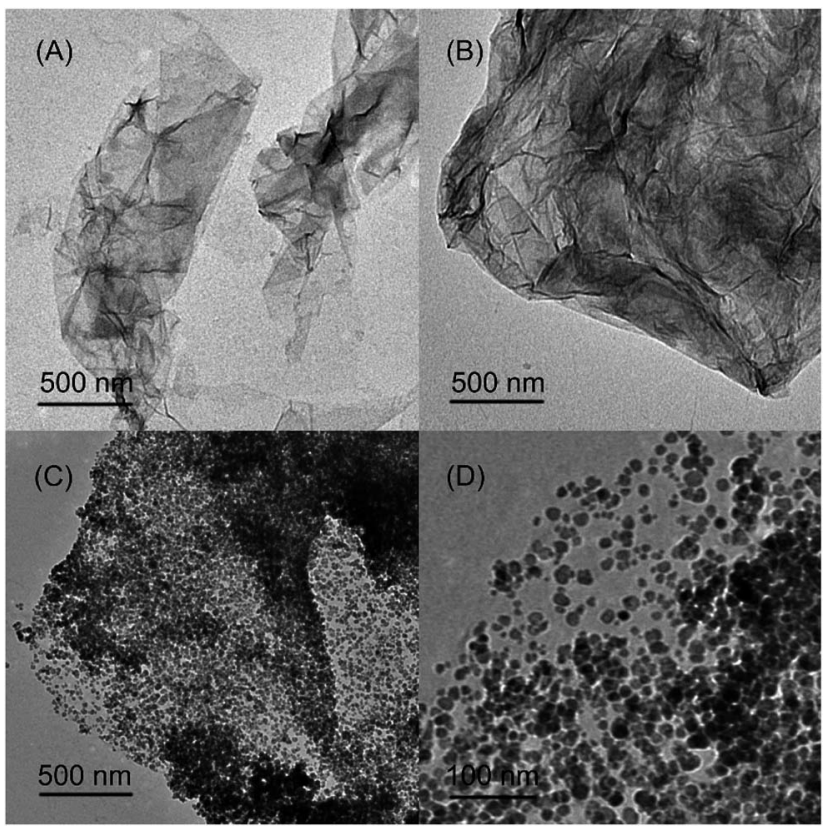

Fig. 4 TEM images of (A) GO, (B) AMGO-Glu, (C) AMGO-Glu@ $\mathrm{Fe}_{3} \mathrm{O}_{4}$ and (D) AMGO-Glu@ $\mathrm{Fe}_{3} \mathrm{O}_{4}$

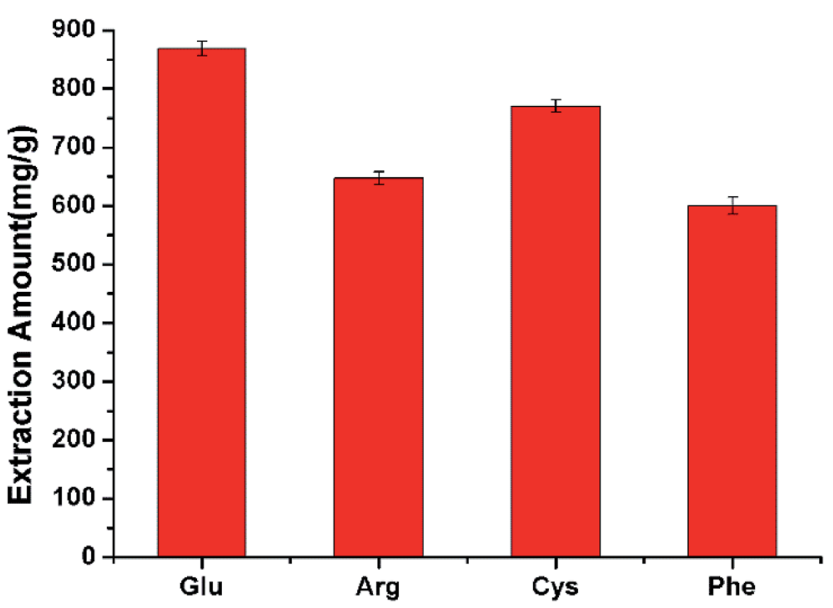

Fig. 5 Effect of the type of amino acid on the extraction of bovine hemoglobin (BHb). Glu, glutamic acid; Arg, L-arginine; Cys, cysteine; Phe, phenylalanine.

kinds of amino acid were modified on GO, their different functional groups would have different interactions with protein. As phenylalanine was grafted on GO, the introduction of the benzene ring would enhance the $\pi-\pi$ interaction on protein. On the other hand, L-arginine would strengthen hydrogen bonding interaction and change the electrostatic interaction owing to the existence of $-\mathrm{NH}_{2}$, and cysteine and glutamic acid would increase the negative charge on the surface and enhance the electrostatic interaction between protein and adsorbent. As AMGO-Glu@Fe $\mathrm{O}_{4}$ was extracted in the greatest quantity, electrostatic interaction may be the main driving force, and AMGO-Glu@ $\mathrm{Fe}_{3} \mathrm{O}_{4}$ was selected for use in further experiments.
3.2.2 Effect of $\mathbf{p H}$ value. The $\mathrm{pH}$ value played an important role in the extraction capacity of protein in the magnetic separation procedure. It could influence the conformation of protein and the charges on both protein and adsorbent. The $\mathrm{pH}$ value was varied from 3.0 to 10.0 using PBS buffer solution $(0.05 \mathrm{~mol}$ $\mathrm{L}^{-1}$ ) and the results are shown in Fig. 6A. It can be seen that the amount extracted reached a maximum at $\mathrm{pH}$ 6.0. This was because, at pH 6.0, the AMGO-Glu@ $\mathrm{Fe}_{3} \mathrm{O}_{4}$ was highly anionic, but $\mathrm{BHb}(\mathrm{pI}=6.8$ ) was highly cationic, as shown in Fig. 7. The electrostatic attraction led to the high extraction capacity. However, with $\mathrm{pH}>6.0$, the amount of $\mathrm{BHb}$ extracted decreased sharply with increasing $\mathrm{pH}$ value. This could be attributed to the fact that the surfaces of $\mathrm{BHb}$ and AMGO-Glu@ $\mathrm{Fe}_{3} \mathrm{O}_{4}$ were both negatively charged when the $\mathrm{pH}$ was greater than the $\mathrm{pI}$ of $\mathrm{BHb}$. Although there were hydrogen bonding and $\pi-\pi$ interactions between AMGO-Glu@ $\mathrm{Fe}_{3} \mathrm{O}_{4}$ and $\mathrm{BHb}$, the electrostatic repulsion interaction was much stronger and reduced the extraction performance of the adsorbent. In addition, a higher $\mathrm{pH}$ value could weaken hydrogen bonds between protein and adsorbent. As the extracted amount reached its maximum at $\mathrm{pH}$ 6.0, a solution $\mathrm{pH}$ value of 6.0 was chosen for further experiments.

3.2.3 Effect of the addition of electrolyte. The influence of the addition of electrolyte on extraction capacity was investigated using PBS buffer solutions with different concentrations of $\mathrm{NaCl}\left(0.0-0.5 \mathrm{~mol} \mathrm{~L}^{-1}\right)$. As shown in Fig. 6B, the extraction capacity of $\mathrm{BHb}$ decreased with the increase in concentration of $\mathrm{NaCl}$. The negative impact might be ascribed to the electrostatic interaction between protein and adsorbent. Under the conditions of solution, BHb with positive charges on its surface attracted negative ions in the solution, which would reduce the electrostatic attraction between $\mathrm{BHb}$ and $\mathrm{AMGO}-\mathrm{Glu} @ \mathrm{Fe}_{3} \mathrm{O}_{4}$. With the increase in concentration of $\mathrm{NaCl}$, the salt ions strongly shielded the electrostatic attraction, making it difficult to adsorb and rearrange protein on the surface of the adsorbent, and decreasing the extraction efficiency. As the addition of $\mathrm{NaCl}$ could not increase the extraction capacity of protein, $\mathrm{NaCl}$ was not added in further experiments.

3.2.4 Effect of extraction time. In order to obtain an appropriate adsorption time, the experiment was carried out with different extraction times, and the results are presented in Fig. 6C. It can be seen that a large amount of $\mathrm{BHb}$ could be adsorbed within 5 minutes, which exhibited the superior adsorption capacity of AMGO-Glu@ $\mathrm{Fe}_{3} \mathrm{O}_{4}$. In the following $35 \mathrm{~min}$, protein adsorption increased gradually and after $40 \mathrm{~min}$, the amount extracted reached equilibrium and did not change significantly with increasing time after that. This could be interpreted by the fact that AMGO-Glu@ $\mathrm{Fe}_{3} \mathrm{O}_{4}$ had many adsorption sites on its surface at the start, so that the protein could be easily adsorbed. As time progressed, more and more adsorption sites had been occupied, so the adsorption process slowed down and eventually reached equilibrium. Since the extraction process reached equilibrium at $40 \mathrm{~min}$, this was selected as the optimum extraction time.

3.2.5 Effect of protein concentration. The effect of protein concentration was studied using different initial BHb concentrations, with values in the range $0.1-2.0 \mathrm{mg} \mathrm{mL}^{-1}$. In order to 
(A)

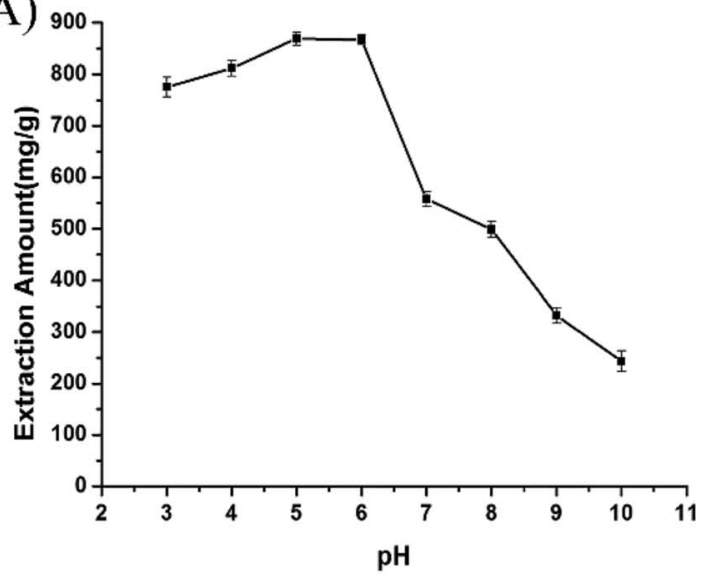

(C)

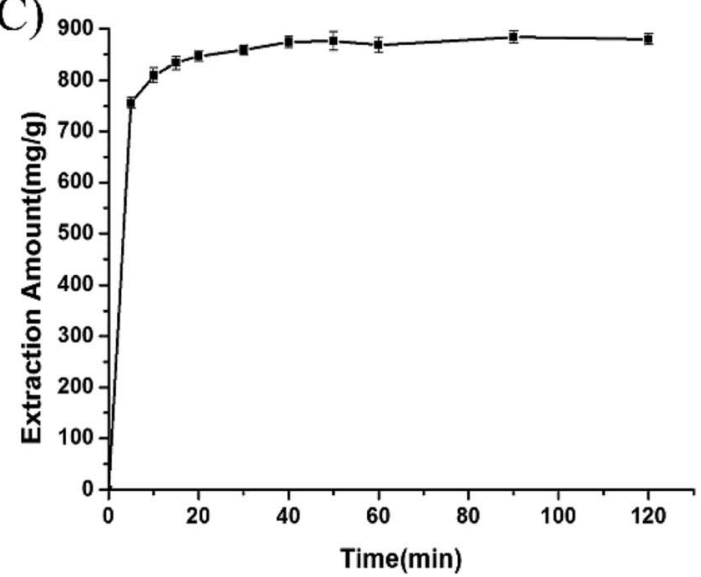

(B)

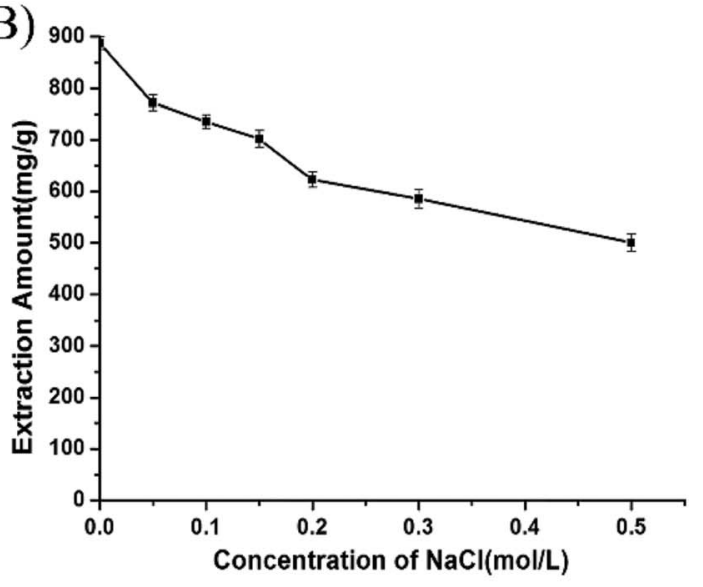

(D)

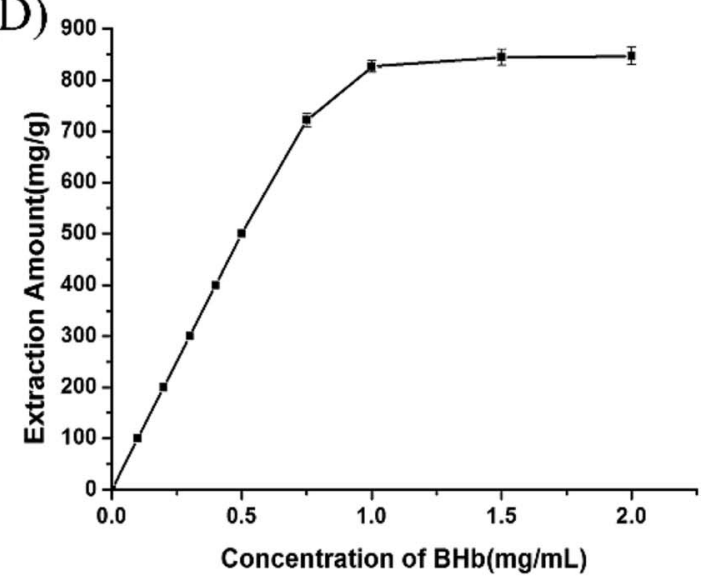

Fig. 6 Effects of extraction conditions. (A) Effect of $\mathrm{pH}$ : protein concentration, $1 \mathrm{mg} \mathrm{mL}^{-1}$; concentration of $\mathrm{NaCl}, 0.0 \mathrm{~mol} \mathrm{~L}-1$; extraction time, $1 \mathrm{~h}$. (B) Effect of the solution ionic strength: protein concentration, $1 \mathrm{mg} \mathrm{mL}^{-1}$; extraction time, $1 \mathrm{~h}$; solution pH 6.0. (C) Effect of extraction time: protein concentration, $1 \mathrm{mg} \mathrm{mL}^{-1}$; concentration of $\mathrm{NaCl}, 0.0 \mathrm{~mol} \mathrm{~L}-1$; solution $\mathrm{pH}$ 6.0. (D) Effect of protein concentration: concentration of $\mathrm{NaCl}, 0.0 \mathrm{~mol} \mathrm{~L}^{-1}$; extraction time, $1 \mathrm{~h}$; solution $\mathrm{pH} 6.0$.

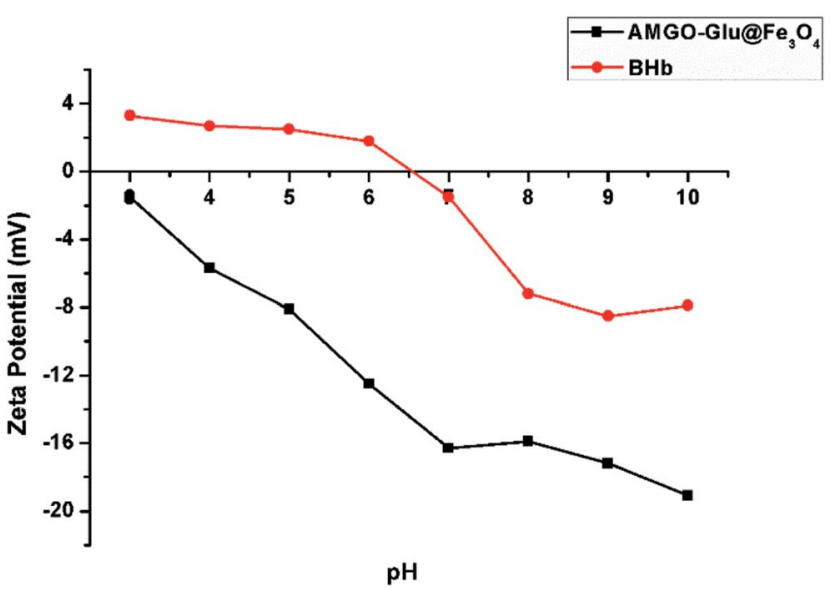

Fig. 7 Zeta potentials of $\mathrm{AMGO}-\mathrm{GluaFe} \mathrm{F}_{3} \mathrm{O}_{4}$ and $\mathrm{BHb}$ under different $\mathrm{pH}$ values.

guarantee the attainment of adsorption equilibrium, the extraction time was chosen to be $1 \mathrm{~h}$. As can be seen from Fig. 6D, the extraction amount increased linearly with the increase in protein concentration, and almost all of the protein in the solution was adsorbed on the surface of the adsorbent when the concentration of protein was less than $0.5 \mathrm{mg} \mathrm{mL}{ }^{-1}$. This is because there were sufficient adsorption sites on AMGOGlu@ $\mathrm{Fe}_{3} \mathrm{O}_{4}$ to extract all of the protein at lower concentrations, and the extraction amount was only dependent on the amount of protein in the solution. When the initial concentration was in the range $0.5-1.0 \mathrm{mg} \mathrm{mL}^{-1}$, the upward trend turned to gradual, and then the extraction capacities remained almost constant with concentrations greater than $1.0 \mathrm{mg} \mathrm{mL} \mathrm{m}^{-1}$. The results indicated that the adsorption capacity of AMGO-Glu@ $\mathrm{Fe}_{3} \mathrm{O}_{4}$ was limited, and the adsorption sites were saturated when the concentration was greater than $1.0 \mathrm{mg} \mathrm{mL} \mathrm{mL}^{-1}$. Therefore, concentrations less than $1.0 \mathrm{mg} \mathrm{mL} \mathrm{m}^{-1}$ could be selected as an appropriate value for the $\mathrm{BHb}$ concentration.

\subsection{Comparison of GO@ $\mathrm{Fe}_{3} \mathrm{O}_{4}$ and AMGO-Glu@ $\mathrm{Fe}_{3} \mathrm{O}_{4}$}

$\mathrm{GO} @ \mathrm{Fe}_{3} \mathrm{O}_{4}$ and AMGO-Glu@ $\mathrm{Fe}_{3} \mathrm{O}_{4}$ were used to adsorb proteins under the same conditions to evaluate the advantage of the proposed AMGO-Glu@ $\mathrm{Fe}_{3} \mathrm{O}_{4}$. It can be seen from Fig. 8 that 


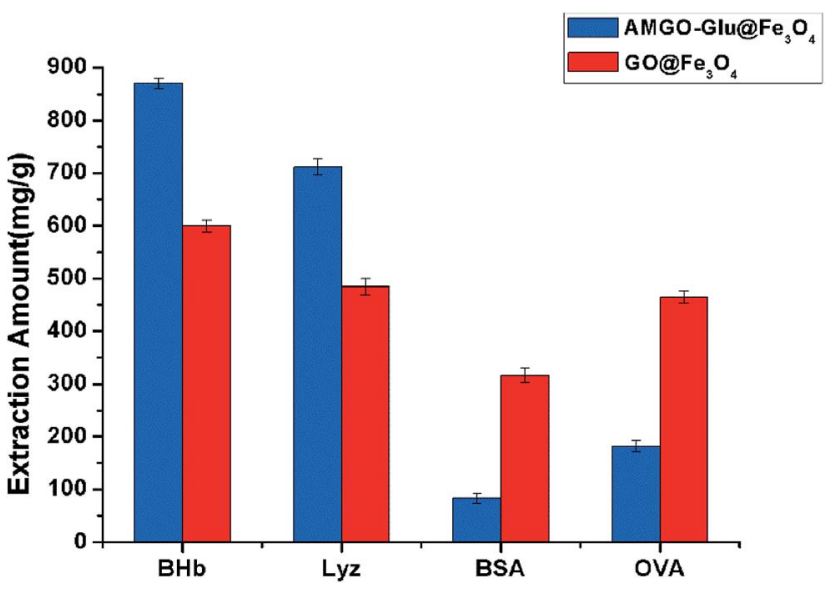

Fig. 8 Comparison of protein extraction ability of $\mathrm{GO}_{\mathrm{aFe}} \mathrm{O}_{4}$ and AMGO-Glua $\mathrm{Fe}_{3} \mathrm{O}_{4}$.

both adsorbents had the ability to extract proteins, but their extraction capacities were different. Because of the conjugated structure and the existence of oxygenated groups on GO, the $\mathrm{GO} @ \mathrm{Fe}_{3} \mathrm{O}_{4}$ could form electrostatic, hydrogen bonding and $\pi-$ $\pi$ interactions with proteins. When glutamic acid was modified on the surface of GO, the extraction capacities of BHb and Lyz increased. This may be because the carboxyl groups in glutamic acid could increase the negative charge on the surface after modification. As shown in Fig. 9, the zeta potentials of GO@ $\mathrm{Fe}_{3} \mathrm{O}_{4}$ and AMGO-Glu@ $\mathrm{Fe}_{3} \mathrm{O}_{4}$ were $-6.8 \mathrm{mV}$ and $-14.1 \mathrm{mV}$, respectively. In addition, the chosen $\mathrm{pH}$ value of extraction was 6.0, so the $\mathrm{BHb}(\mathrm{pI}=6.8)$ and $\mathrm{Lyz}(\mathrm{pI}=11.0)$ were positively charged. The increase in negative charge could enhance the electrostatic attraction between protein and the adsorbent, which improved the extraction capacities. However, under the same $\mathrm{pH}$ value, $\mathrm{BSA}(\mathrm{pI}=4.8)$ and OVA ( $\mathrm{pI}=4.7)$ were negatively charged, and the increase in negative charge could strengthen the electrostatic repulsion, so that the extraction capacities decreased. Moreover, the adsorption ratios of $\mathrm{BHb} /$ BSA and BHb/OVA were 10.54 and 4.79, respectively, which indicated that AMGO-Glu@ $\mathrm{Fe}_{3} \mathrm{O}_{4}$ could selectively extract $\mathrm{BHb}$ from an acidic protein mixture.

\subsection{Regeneration of the AMGO@ $\mathrm{Fe}_{3} \mathrm{O}_{4}$}

In order to explore the regeneration of AMGO-Glu@ $\mathrm{Fe}_{3} \mathrm{O}_{4}$, a series of desorption experiments were performed. It can be seen in Sections 3.2.2 and 3.2.3 that an increase in $\mathrm{pH}$ value and concentration of $\mathrm{NaCl}$ could decrease the amount of $\mathrm{BHb}$ extracted. In addition, the hydrogen bonds between AMGOGlu@ $\mathrm{Fe}_{3} \mathrm{O}_{4}$ and $\mathrm{BHb}$ could be broken under alkaline conditions. Therefore, $0.05 \mathrm{~mol} \mathrm{~L}^{-1}$ PBS buffer solution ( $\mathrm{pH}$ 11.0) containing $0.5 \mathrm{~mol} \mathrm{~L}^{-1} \mathrm{NaCl}$ was chosen as the eluent. After desorption, the AMGO-Glu@Fe $\mathrm{O}_{4}$ was recovered by an external magnetic field and washed 3 times with deionized water, then it was utilized to extract $\mathrm{BHb}$ again. Three consecutive extraction-desorption cycles were carried out and the results are shown in Fig. S2. $\uparrow$ The results showed only a minor decrease in the extraction capacity after three consecutive cycles, indicating the good recyclability of the proposed AMGO-Glu@ $\mathrm{Fe}_{3} \mathrm{O}_{4}$ in magnetic separation.

\subsection{Extraction selectivity}

In order to examine the possibility of selective extraction of $\mathrm{BHb}$ based on AMGO-Glu@ $\mathrm{Fe}_{3} \mathrm{O}_{4}$, a protein mixture including BSA and $\mathrm{BHb}$ was used as a model. Meanwhile, the extraction selectivity of $\mathrm{GO} @ \mathrm{Fe}_{3} \mathrm{O}_{4}$ was explored under the same conditions for comparison. After adsorption and desorption, the supernatants were both collected for analysis by sodium dodecyl sulfate polyacrylamide gel electrophoresis (SDS-PAGE) assay. The results are shown in Fig. S3. $\uparrow$ For GO@Fe $\mathrm{O}_{4}$, the presence of protein was not observed in the supernatant after adsorption (lane 3), whereas both the BSA band around $66 \mathrm{kDa}$ and the $\mathrm{BHb}$ band around $14 \mathrm{kDa}$ were found in the eluent (lane $5)$. The results showed that both $\mathrm{BHb}$ and BSA were adsorbed by $\mathrm{GO} @ \mathrm{Fe}_{3} \mathrm{O}_{4}$, which indicated that the protein extraction of $\mathrm{GO} @ \mathrm{Fe}_{3} \mathrm{O}_{4}$ was nonspecific. On the other hand, after adsorption by AMGO-Glu@ $\mathrm{Fe}_{3} \mathrm{O}_{4}$, only the BSA band was discovered in the supernatant (lane 4), while in the recovered eluent, only the
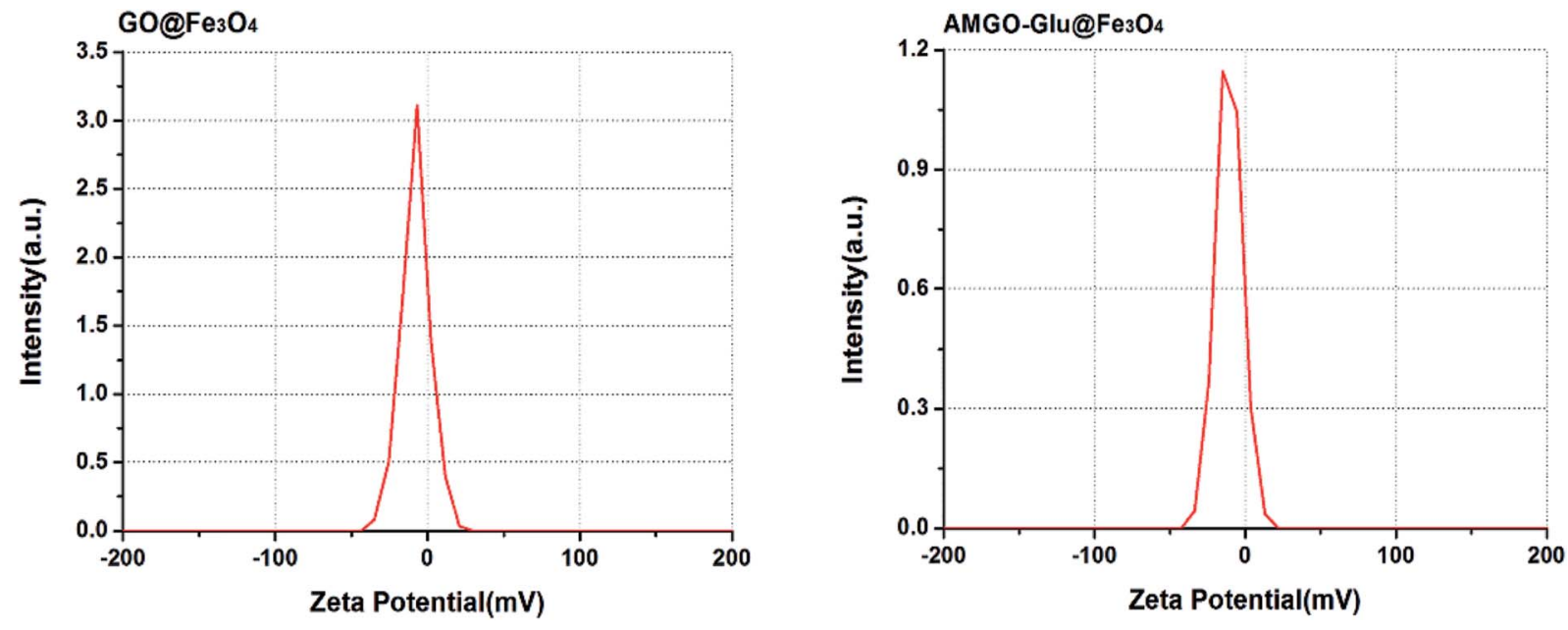

Fig. 9 Zeta potentials of $\mathrm{GO} a \mathrm{Fe}_{3} \mathrm{O}_{4}$ and $\mathrm{AMGO}-\mathrm{Glu}\left(\mathrm{Fe}_{3} \mathrm{O}_{4}\right.$. 
$\mathrm{BHb}$ band was observed (lane 6). The results showed that AMGO-Glu@ $\mathrm{Fe}_{3} \mathrm{O}_{4}$ could selectively extract $\mathrm{BHb}$ from BSA.

\subsection{Analysis of real samples}

To evaluate the performance of AMGO-Glu@ $\mathrm{Fe}_{3} \mathrm{O}_{4}$ in real samples, the nanocomposite was used to extract $\mathrm{BHb}$ from bovine plasma. After adsorption and desorption, the supernatants were both collected for analysis by SDS-PAGE assay. As shown in Fig. $\mathbf{S} 4, \dagger$ some protein bands were recorded for the bovine plasma sample (lane 2), which may be attributed mainly to $\mathrm{BSA}, \mathrm{BHb}$, transferrin and so on. After adsorption by AMGOGlu@ $\mathrm{Fe}_{3} \mathrm{O}_{4}$, the bands were still observed in the supernatant (lane 3). This is because the amount of proteins in bovine plasma was excessive for the adsorbent; however, in the recovered eluent, lane 4 showed a major band corresponding to 14 $\mathrm{kDa}$, which was identified as $\mathrm{BHb}$. The results showed that AMGO-Glu@Fe $\mathrm{O}_{4}$ could selectively extract $\mathrm{BHb}$ in complex real samples.

\subsection{Validation of the proposed method}

To evaluate the analytical performance of the proposed method, stability, repeatability and precision experiments were carried out. The stability experiment was performed by detecting a sample continuously over 3 days under the same conditions and the relative standard deviation (RSD) was $1.00 \%(n=3)$. The repeatability experiment was performed by monitoring three copies of the same sample under the same conditions and the RSD was $0.76 \%(n=3)$. The apparatus precision experiment was performed by measuring the same sample three times using a UV-vis spectrophotometer, and the value of RSD was $0.02 \%$ ( $n$ $=3$ ). The results indicated the proposed method possessed excellent precision, repeatability, and stability.

\section{Conclusions}

A novel amino acid-modified GO magnetic nanocomposite AMGO@ $\mathrm{Fe}_{3} \mathrm{O}_{4}$ was successfully synthesized for the magnetic separation of proteins. The material displayed good magnetic properties and proteins could be separated rapidly using an external magnet. The research results showed that the AMGO@Fe $\mathrm{O}_{4}$ was superior to $\mathrm{GO} @ \mathrm{Fe}_{3} \mathrm{O}_{4}$ in the extraction of $\mathrm{BHb}$ and Lyz, and could selectively extract $\mathrm{BHb}$ from BSA in complex real samples. Moreover, the $\mathrm{AMGO} @ \mathrm{Fe}_{3} \mathrm{O}_{4}$ could be easily regenerated, and the extraction capacity decreased only slightly after being used three times. The proposed method possessed excellent precision, repeatability and stability, and could be used as a simple and efficient separation technique for proteins in real samples.

\section{Conflict of interest}

The authors have declared no conflict of interest.

\section{Acknowledgements}

This work was supported by the Natural Science Foundation of China (No. 21575076 and 21621003), the National Key Research and Development Program of China (2016YFA0203101), and the Beijing Municipality Science and Technology Program (D161100002116001).

\section{References}

1 Y. Huang, Y. Wang, Q. Pan, Y. Wang, X. Ding, K. Xu, N. Li and Q. Wen, Anal. Chim. Acta, 2015, 877, 90-99.

2 H. Wang and S. Hanash, Mass Spectrom. Rev., 2005, 24, 413426.

3 Y. Huang, Y. Wang, Y. Wang, Q. Pan, X. Ding, K. Xu, N. Li and Q. Wen, RSC Adv., 2016, 6, 5718-5728.

4 M. Wierucka and M. Biziuk, TrAC, Trends Anal. Chem., 2014, 59, 50-58.

5 W. Wan, Q. Han, X. Zhang, Y. Xie, J. Sun and M. Ding, Chem. Commun., 2015, 51, 3541-3544.

6 M. Safarikova, I. Kibrikova, L. Ptackova, T. Hubka, K. Komarek and I. Safarik, J. Magn. Magn. Mater., 2005, 293, 377-381.

7 K. Xu, Y. Wang, Y. Li, Y. Lin, H. Zhang and Y. Zhou, Anal. Chim. Acta, 2016, 946, 64-72.

8 H. Su, Y. Lin, Z. Wang, Y.-L. E. Wong, X. Chen and T.-W. D. Chan, J. Chromatogr. A, 2016, 1466, 21-28.

9 Y. Cai, Z.-H. Yan, N.-Y. Wang, Q.-Y. Cai and S.-Z. Yao, RSC Adv., 2015, 5, 56189-56197.

10 M. Rashvand, M. Vosough and K. Kargosha, RSC Adv., 2016, 6, 75609-75617.

11 X. Zhang, H. Niu, Y. Pan, Y. Shi and Y. Cai, Anal. Chem., 2010, 82, 2363-2371.

12 J. Ma, L. Jiang, G. Wu, Y. Xia, W. Lu, J. Li and L. Chen, J. Chromatogr. A, 2016, 1466, 12-20.

13 Z. Shan, Z. Zhou, H. Chen, Z. Zhang, Y. Zhou, A. Wen, K. D. Oakes and M. R. Servos, J. Chromatogr. B: Anal. Technol. Biomed. Life Sci., 2012, 881, 63-68.

14 L. Wang, M. Wang, H. Yan, Y. Yuan and J. Tian, J. Chromatogr. A, 2014, 1368, 37-43.

15 Y. Lu, W. Chen, Y. Feng and P. He, J. Phys. Chem. B, 2008, 113, 2-5.

16 C. Lee, X. Wei, J. W. Kysar and J. Hone, Science, 2008, 321, 385-388.

17 S. Stankovich, D. A. Dikin, G. H. Dommett, K. M. Kohlhaas, E. J. Zimney, E. A. Stach, R. D. Piner, S. T. Nguyen and R. S. Ruoff, Nature, 2006, 442, 282-286.

18 A. K. Singh and B. I. Yakobson, Nano Lett., 2009, 9, 15401543.

19 L. Xu, H. Suo, X. Liang, L. Wang and S. Jiang, RSC Adv., 2015, 5, 41536-41543.

20 H. Ahmad, A. A. Jalil and S. Triwahyono, $R S C A d v ., 2016,6$, 88110-88116.

21 L. Zhu and H. Xu, J. Sep. Sci., 2014, 37, 2591-2598.

22 Y. Li, L. Qi and H. Ma, Analyst, 2013, 138, 5470-5478.

23 X. Chen, X. Hai and J. Wang, Anal. Chim. Acta, 2016, 922, 110.

24 N. Ye and P. Shi, Sep. Purif. Rev., 2015, 44, 183-198.

25 Q. Liu, J. B. Shi, L. X. Zeng, T. Wang, Y. Q. Cai and G. B. Jiang, J. Chromatogr. A, 2011, 1218, 197-204. 
26 J. Sun, Q. Liang, Q. Han, X. Zhang and M. Ding, Talanta, 2015, 132, 557-563.

27 Q. Min, X. Zhang, H. Zhang, F. Zhou and J.-J. Zhu, Chem. Commun., 2011, 47, 11709-11711.

28 G. Cheng, Y.-L. Liu, Z.-G. Wang, J.-L. Zhang, D.-H. Sun and J.-Z. Ni, J. Mater. Chem., 2012, 22, 21998-22004.
29 X. Ding, Y. Wang, Y. Wang, Q. Pan, J. Chen, Y. Huang and K. Xu, Anal. Chim. Acta, 2015, 861, 36-46.

30 S. Mallakpour, A. Abdolmaleki and S. Borandeh, Appl. Surf. Sci., 2014, 307, 533-542.

31 W. S. Hummers and R. E. Offeman, J. Am. Chem. Soc., 1958, 80, 1339. 